\title{
YIELD UNCERTAINTY AND MILK SUPPLY RESPONSE IN TWO-TIER PRICE SYSTEMS
}

\author{
DANIEL MULUWORK ATSBEHA* \\ Norwegian Institute of Bioeconomy Research (NIBIO), Aas, Norway
}

\begin{abstract}
In two-tier price systems, yield uncertainty creates incentives to overproduce quantity-restricted outputs even when prices for surplus output are very low. These incentives arise from precautionary motives against expected losses from quota shortfalls. Using an approach augmented for multiple input applications, the likelihood of excess production and the relative importance of price changes in different markets are estimated for Icelandic dairy farms. The results indicate that the average farm plans to exceed its quota, and price changes in the surplus milk market are approximately three times more effective in generating supply response than price changes in the quota milk market.
\end{abstract}

Keywords. Dairy quota, milk yield, production risk, supply response, two-tier price system, yield uncertainty

JEL Classification. D22, Q12, Q13

\section{Introduction}

One way quota programs imposed on producers are enforced is a two-tier price system. Under this system, a quota-restricted output receives different prices depending on whether it is delivered inside or outside the quota. Usually prices for surplus output are unprofitably low. However, producers may still plan to overproduce their allotted quota if yields are uncertain (Fraser, 1986, 1995). Such excess production protects producers from two potential losses that are associated with yield uncertainty (Alston and Quilkey, 1980). These losses are the loss of revenue from forgone sales when quota shortfalls occur and the loss of unused quota in future allocations of production rights. In the context of

\footnotetext{
Daniel Muluwork Atsbeha is a researcher at the Norwegian Institute of Bioeconomy Research (NIBIO). Most of the work for this article was conducted when the author was working for the School of Economics and Business at Norwegian University of Life Sciences. Part of this work is also supported by NIBIO under the SIS-PEAP project financed by the Research Council of Norway. Comments from Kyrre Rickertsen and Dadi Kristofersson, as well as Atle Guttormsen, Subal Kumbhakar, and Erik Biørn, are greatly appreciated. The author also expresses gratitude to the Agricultural Economics Institute of Iceland for providing the data set used for the analysis.

*Corresponding author’s e-mail: daniel.muluwork.atsbeha@nibio.no
} 
dairy production, Alston and Quilkey (1980) termed such excess production as "insurance milk."

Fraser $(1986,1995)$ provided a more formal treatment of yield uncertainty when modeling the relationship between planned production and yield uncertainty. Babcock (1990) extended the treatment to risk-averse producers. Building on Babcock's framework, Borges and Thurman (1994) proposed an approach to compute the probability of planned production exceeding quota and the relative importance of price incentives for supply response in the two-tier price setup. Using data from peanut production in North Carolina, Borges and Thurman (1994) found that planned production was likely to exceed the quota with a high probability, ranging from 0.87 to 0.97 . Furthermore, the relative importance of price changes in the quota peanut market for supply response was at least 30 times higher compared with equivalent price changes in the surplus peanut market.

Similar empirical studies are lacking for the dairy sector. This deficiency is surprising given that the pioneering work of Alston and Quilkey (1980) was on dairy production, and milk supply management using marketing quotas has been pervasive (e.g., in Canada, the European Union until April 2015, Norway, Iceland, and California in the United States). Furthermore, though to a lesser extent, dairy production can be affected by yield uncertainty, arising from different sources. For example, in relatively small dairy enterprises, a significant portion of forage is produced on the farm. The implication is that weather-related risks that are usually associated with crop production can also be sources of yield uncertainty in dairy production. Weather-related sources of uncertainty are especially likely in areas where dairy production takes place under difficult agroecological conditions. In such cases, adverse weather can also have implications beyond forage production such as on animal health because dairy cows may have to be kept indoors for extended periods of time (Jóhannesson, 2010). Other sources of milk yield uncertainty are random occurrences of dairy cow diseases such as mastitis, death of cows, incorrect detection of ovulation for artificial insemination, and optimization errors.

This article has four objectives. First, the Borges and Thurman (1994) model is augmented to consider multiple inputs. The consideration of multiple inputs is important for two reasons. First, when any single input is chosen to compute yield in a multiple input setting, the underlying assumption is that the probability distribution of yield per this single input is unaffected by the application of the remaining inputs (Babcock, 1990). However, the probability distribution of yield per any single input in agriculture is likely to be affected by the application of other inputs. For example, Nelson and Preckel (1989) showed that the application of fertilizer in five Iowa counties had a significant effect on the first three moments of a corn yield distribution. Similarly, Babcock and Hennessy (1996) found that the application of fertilizer up to 200 pounds an acre decreased the probability of low yields on experimental Iowa corn farms. Second, yield data 
constructed based on a single input portray the chosen input as more productive than it actually is as long as the marginal product of all other inputs is positive. To the contrary, farmers are likely to perceive the chosen input as less productive than portrayed by the yield data. An implication is that the observed level of the chosen input is larger than what farmers would have used if they had perceived it as productive as implied by the yield data. Because the observed input levels are used to infer planned production, the seemingly overapplication of the chosen input will exaggerate the likelihood of overproduction. ${ }^{1}$

With the increasing availability of detailed farm management data, one way to address these problems is to compute yield levels in such a manner that the contribution of other inputs to total output is accounted for. This result is achieved by computing yield per aggregate input rather than any particular single input. Aggregation over multiple inputs is achieved using weights obtained from a parametric production frontier. In addition to facilitating the aggregation of inputs, estimating a parametric frontier has an additional benefit in the context of yield density estimation. This benefit relates to the fact that yield data come from farms that are not always fully technically efficient. Therefore, by providing farm- and time-specific technical efficiency scores, the estimation of a parametric frontier facilitates data pooling under fewer assumptions than are required when aggregate data are used.

Using the augmented approach, a second objective is to compute the probability of planned production exceeding quota on Icelandic dairy farms. Third, the relative marginal importance of price changes in the quota and surplus milk markets is computed. These estimates are the primary policy-relevant outputs of this exercise because they are useful for evaluating, for instance, the supply effects of price changes in the quota milk market, which are usually determined administratively. Finally, the implication of allowing for multiple inputs is evaluated by comparing the results from the augmented approach with the results from an approach that considers a single input only.

\section{Model}

The theoretical model used in this article is a modified version of the model in Borges and Thurman (1994). The modification relates to the lack of opportunities for Icelandic dairy farms to carry over their unused milk quota to a subsequent production period..$^{2}$ In the remainder of this section, the Borges and Thurman

1 This effect is presented in detail and graphically in Appendix A.

2 As indicated correctly by a referee, the possibility to rent quotas can affect the precautionary motives of the farmer and, therefore, the likelihood of overproduction. However, in the Icelandic case there is only a quota sales market, and short-term quota rentals are illegal. However, the scale adjustment the quota sales market allows may still exaggerate the chances of precautionary overproduction if there are investments for additional production capacity. The reverse could be true for farms scaling down their production capacity, for example, because of retirement plans. 
(1994) model based on an aggregate input is presented first. A discussion on the construction of the aggregate input follows.

\subsection{Probability of Surplus Production and Relative Marginal Importance of Price Changes}

Let $y$ be the milk yield per unit of an aggregate input $x$, and $Y$ be the total milk that is produced by a dairy farm, which is constrained by a farm-level quota $q$. Then, $q / x$ is the yield that is required per unit of an aggregate input to meet the quota exactly or the yield requirement. Yield is random, and $f(y)$ is its probability density function. Consequently, $Y=x \cdot y$, and the production problem of the farm reduces to a choice of aggregate input quantity. In this setting, the observed levels of the aggregate input provide information concerning the unobservable planned production given the yield density, which then allows evaluation of planned production relative to each farm's quota. For example, if the yield requirement is smaller than the expected yield at the chosen level of the aggregate input, then we can infer that the dairy farm must have planned to overproduce its quota.

Under risk neutrality, no price uncertainty, and no carryover of unused quota, the economic problem of the dairy farm can be presented as a maximization of expected profit, as given in Borges and Thurman (1994):

$$
\begin{aligned}
E(\Pi)= & \int_{0}^{q / x}\left[p_{q} x y\right] f(y) d y \\
& +\int_{q / x}^{\infty}\left[p_{q} q+p_{a}(x y-q)\right] f(y) d y-C(x),
\end{aligned}
$$

where $p_{q}$ is the milk price in the quota milk market, $p_{a}$ is the milk price in the surplus milk market, and $C(x)$ is the cost of employing $x$. That is, the expected profit is the excess of a weighted sum of revenues over production cost. The probabilities that the milk yield will be within or above the quota are used as weights. As in Borges and Thurman (1994), $\Phi=\int_{q / x}^{\infty} f(y) d y$ is an estimate of the probability that planned production may exceed the farm's quota.

Following the same procedure as in Borges and Thurman (1994), the relative marginal importance of price changes in the quota and surplus milk markets would be the following: ${ }^{3}$

$$
\begin{gathered}
\Theta_{q}=\frac{\partial x / \partial p_{q}}{\partial x / \partial p_{q}+\partial x / \partial p_{a}}=\frac{\int_{0}^{q / x} y f(y) d y}{\int_{0}^{\infty} y f(y) d y}, 0 \leq \Theta_{q} \leq 1, \\
\Theta_{a}=1-\Theta_{q} .
\end{gathered}
$$

3 The derivation of $\Theta_{q}$ is the same as in Borges and Thurman (1994). 
$\Theta_{q}$ measures the relative marginal importance of a price change in the quota milk market relative to an equivalent and simultaneous price change in the quota and surplus milk markets. Therefore, $\Theta_{q}$ implies the increasing importance of price changes in the quota milk market as it gets closer to unity and vice versa. Furthermore, as noted by Borges and Thurman (1994), $\lim _{q / x \rightarrow 0} \Theta_{q}=0$ and $\lim _{q / x \rightarrow \infty} \Theta_{q}=1$. This outcome is intuitive because for a given quota size, the relative marginal importance of a price change in the quota milk market decreases as $q / x$ gets smaller, which indicates a producer that is planning to overproduce its quota. In contrast, when a producer seeks to avoid overproduction, $q / x$ increases and the relative marginal importance of a price change in the quota milk market increases.

\subsection{Construction of Aggregate Input}

In this section, the construction of weights required to compute an aggregate input is presented. Given that yield data imply a technical relation between an input and an output, an obvious candidate for generating aggregation weights is a production frontier. A production frontier represents the best available technique for transforming inputs into outputs. To obtain an econometric estimate of the production frontier, a mathematical relation between inputs and an output is specified in a translog form, which provides a second-order approximation to any unknown function (Christensen, Jorgenson, and Lau, 1973):

$$
\begin{aligned}
\ln Y_{i t}= & \alpha_{0}+\sum_{j=1}^{n} \alpha_{j} \ln x_{j i t}+\rho t+\frac{1}{2} \sum_{j=1}^{n} \sum_{k=1}^{n} \alpha_{j k} \ln x_{j i t} \ln x_{k i t} \\
& +\sum_{j=1}^{n} \alpha_{j t} t \ln x_{j i t}+\frac{1}{2} \rho_{t t} t^{2}+\varepsilon_{i t} .
\end{aligned}
$$

The $x_{j i t}$ 's are the $j$ inputs used to produce milk, $t$ is a time trend introduced to capture the effect of technical change, and $\varepsilon_{i t}$ is a composite error term that contains a random noise component, $v_{i t}$, and a nonnegative time-varying technical inefficiency component, $u_{i t}$, or $\varepsilon_{i t}=v_{i t}-u_{i t}$. The farm- and timespecific technical efficiency scores $\left(T E_{i t}\right)$ for each farm are obtained by $T E_{i t}=$ $\exp \left(-u_{i t}\right)$. Following Battese and Coelli (1992), the temporal pattern of technical inefficiency is specified as $u_{i t}=\exp \{-\eta(t-T)\} \cdot u_{i}$, where $\eta$ is a decay parameter and $T$ is the terminal period in the data. When $\eta>0$, technical efficiency increases over time, and it decreases when $\eta<0$. Furthermore, the random noise term $v_{i t}$ is symmetrical and assumed to be normally distributed-that is, $v_{i t} \sim N\left(0, \sigma_{v}^{2}\right)$. In contrast, technical inefficiency is assumed to follow a truncated normal distribution; that is, $u_{i} \sim N^{+}\left(\mu, \sigma_{u}^{2}\right)$, which also nests the commonly used halfnormal distribution or $u_{i} \sim N^{+}\left(0, \sigma_{u}^{2}\right)$. Therefore, one can use nested hypothesis testing to choose the distributional assumption that fits the data best. In addition, 
the two error terms are assumed to be independently and identically distributed and orthogonal to one another as well as the independent variables of the model.

Given the parameters of the production frontier, the aggregate input is constructed as follows:

$$
x_{i t}=\sum_{j=1}^{n}\left(\delta_{j i t} / \delta_{i t}\right) \cdot x_{j i t},
$$

where $\delta_{j i t}=\frac{\partial \ln Y_{i t}}{\partial \ln x_{j i t}}$ and $\delta_{i t}=\sum_{j=1}^{n} \delta_{j i t}$. When markets are competitive, inputs are paid their marginal product, and profits are maximum, the weights can be understood as follows (Kim, 1992):

$$
\frac{\delta_{j i t}}{\delta_{i t}}=\frac{\partial \ln Y_{i t} / \partial \ln x_{j i t}}{\sum_{j=1}^{n} \partial \ln Y_{i t} / \partial \ln x_{j i t}}=\frac{w_{j t} x_{j i t}}{C_{i t}},
$$

where $w$ is the input price and $C$ is the minimum cost of production. Therefore, the weights that are attached to each input can also be understood as the cost share of the input from total cost.

\section{Empirical Strategy}

Under the methodology specified, a milk yield density function has to be estimated. However, two problems arise for this estimation. First, ideally, farmlevel yield densities should be estimated (Ker and Coble, 2003). However, a common problem is that yield observations per farm are usually too few to support reliable estimation (Goodwin and Ker, 2002). Therefore, data pooling under certain assumptions, such as equal yield variance, or using yield data from some aggregate levels, such as counties, is commonly considered to ensure sufficient observations for yield density estimations (Borges and Thurman, 1994; Ker and Coble, 2003). The number of observations per farm is also too few in the data used here, and thus data pooling in some form is unavoidable. We start by assuming that the yield density is identical for all farms in a given year, although it may vary across years, for example, because of technical change. However, technical efficiency can vary across farms in a given year as well as over time. ${ }^{4}$ This can be addressed using farm- and time-specific technical efficiency scores that are obtained from equation (3). In particular, the observed output levels are corrected for technical inefficiency as $Y_{i t}^{*}=Y_{i t} / \exp \left(-u_{i t}\right)$, where $Y_{i t}^{*}$ is the output level that will be observed if the farms are technically efficient or $T E=\exp \left(-u_{i t}\right)=1$. Given the emphasis to learn about planned production, generating the yield data based on $Y^{*}$ rather than $Y$ is logical because no rational farm will choose input levels aiming to be technically inefficient.

4 Borges and Thurman (1994) allowed for technical efficiency difference across counties. However, they did not allow for technical efficiency differences over time and for the effects of technical change. 
Under the assumption that technical change affects the expected yield only, while leaving higher moments unaffected, a simple approach is used to handle the effect of technical change. This approach involves three steps: First, the annual average yields are computed and subtracted from the yield data of the respective years. Second, the lowest annual average yield is added back to the demeaned yield data. Finally, the pooled data are used to estimate the yield density function of the year with the lowest annual average yield. Yield density functions of the other years are then recovered by scaling the yield density function of the year with the lowest annual average yield by the difference in average yields between the year under consideration and the least productive year. This approach is the same as the one used by Borges and Thurman (1994) to control for assumed differences in technical efficiency between counties.

A second problem concerning estimating yield densities parametrically relates to the choice of functional form. The literature employs several functional forms to model crop yield densities (Goodwin and Ker, 2002; Ramirez, McDonald, and Carpio, 2010). However, the estimation of yield densities for dairy production is not as common as it is for crop production. One alternative for minimizing a specification error is to use a flexible functional form, such as the Johnson distribution system (Johnson, 1949; Johnson, Kotz, and Balakrishnan, 1994). The Johnson distribution system is a system of four distributions that can accommodate any finite and feasible combination of the first four moments. Consequently, it can approximate a wide range of distributions, including those that are commonly used for modeling crop yield data. Another alternative is to use nonparametric estimation (e.g., see Ker and Coble, 2003; Ker and Goodwin, 2000).

The distributions that form the Johnson family are identified by a set of normalizing transformations that were proposed by Johnson (1949). In particular, given a continuous random variable with an unknown density function, Johnson (1949) proposed a set of normalizing transformations with the general form:

$$
Z=\gamma+\delta \cdot g(u)
$$

to obtain a unit normal distributed variable $Z$. The parameters $\gamma$ and $\delta>0$ are shape parameters, whereas $u=\frac{y-\xi}{\lambda}$, where $\xi$ and $\lambda>0$ are location and scale parameters, respectively. The parameter $g(u)$ is a transformation function that assumes different forms to define the distributions in the Johnson family. These forms are the following (Johnson, 1949; Johnson, Kotz, and Balakrishnan, 1994):

$$
g(u)= \begin{cases}\ln (u), & \text { for the } S_{L} \text { (the log - normal) family } \\ \ln \left[u+\sqrt{u^{2}+1}\right], & \text { for the } S_{U} \text { (unbounded) family, } \\ \ln \left[\frac{u}{(1-u)}\right], & \text { for the } S_{B} \text { (bounded) family, and } \\ u, & \text { for the } S_{N} \text { (normal) family }\end{cases}
$$


As suggested by Hill, Hill, and Holder (1976), the estimated skewness and kurtosis coefficients of the data determine the particular distribution that fits the data best. However, such moment-matching estimators are criticized, for example, because of the sensitivity of the third and fourth moment estimates to outliers (Slifker and Shapiro, 1980). However, other estimators also exist, such as the quantile-based estimator that is suggested by Wheeler (1980) where the best distribution is selected based on five quantiles rather than the first four moments.

Given the previously discussed strategy, the milk yield density function is estimated twice: first based on the yield per aggregate input data and second based on the yield per cow data. The implication of allowing for multiple inputs is then evaluated by comparing the results from the two empirical yield density functions.

\section{Data}

The empirical analysis is based on production data from 324 Icelandic dairy farms that cover the period from 1998 to 2006..$^{5}$ Icelandic dairy farms are small family-owned enterprises with an average herd size of 31 cows in 2006. Iceland is among the countries identified with high support for agricultural producers (Organization for Economic Cooperation and Development, 2007). Consequently, the excess production problem that has followed farm support programs elsewhere also occurred in Iceland in the 1970s, and the need for production control measures had become more apparent by the end of the decade (Agnarsson, 2007).

Nontradable farm-level marketing quotas were then introduced in 1980. However, after the third milk agreement (1992-1997) between the Farmers Association of Iceland and the Ministry of Agriculture, the dairy quota has been freely tradable (Bjarnadottir and Kristofersson, 2008). This change has resulted in the restructuring of the dairy sector toward fewer but larger dairy farms (Bjarnadottir and Kristofersson, 2008). The quota entitles dairy producers to direct payments from the government and higher prices for all milk that is delivered inside the quota according to its composition and hygienic quality. Surplus milk can be sold in a surplus milk market at usually much lower prices that are determined by market forces. Additionally, the quota system requires that dairy farms fill their quota every 2 years or risk losing it. However, it is also possible to obtain permission not to use the quota for a certain time period (Agnarsson, 2007). See Atsbeha, Kristofersson, and Rickertsen (2012) for more details of the Icelandic dairy sector.

5 The raw data contain sensitive farm-level financial information, and its use is subject to strict confidentiality agreements. Therefore, the data cannot be made publicly available. 
Table 1. Descriptive Statistics, 1998-2006

\begin{tabular}{llllll}
\hline \hline Variable & Units & Mean & Standard Deviation & Minimum & Maximum \\
\hline Milk & Liters & $145,442.1$ & $67,556.1$ & $29,249.0$ & $520,137.0$ \\
Concentrates & 1,000 ISK & $1,208.5$ & 692.9 & 41.5 & $5,795.9$ \\
Capital & 1,000 ISK & $2,757.6$ & $1,879.1$ & 292.6 & $17,182.3$ \\
Veterinary services & 1,000 ISK & 218.4 & 151.1 & 2.8 & 998.7 \\
Land & Hectares & 46.9 & 18.1 & 13.0 & 138.0 \\
Number of cows & Cow-years & 31.8 & 12.6 & 4.9 & 115.7 \\
Labor & Months/year & 24.4 & 8.4 & 10.0 & 74.0 \\
Trend & 1998 1 & 5.1 & 2.7 & 1.0 & 9.0 \\
Milk quota & Liters & $141,836.4$ & $66,456.5$ & $30,657.0$ & $562,263.0$ \\
Overproduction & \% of quota & 3.8 & 16.3 & -72.4 & 216.4 \\
\hline \hline
\end{tabular}

Note: 1 USD = ISK 111.2 on November 3, 2016 (http://www.sedlabanki.is).

Of the total sample, there are $63.1 \%$ instances of overproduction. However, surplus production by the average Icelandic farm is small, and it amounts to $3.8 \%$ of the average quota size. To get an idea of how systematic surplus production is, as opposed to optimization error, one can use the Norwegian case. Until 1997, Norway used a two-tier price system and subsequently replaced it with a levy system. Under the levy system, farmers pay penalties for surplus production. However, to allow for optimization errors, a farm can deliver milk up to $102 \%$ of its allocated quota before penalties apply. If the same allowance is used for Icelandic dairy farms, one can easily see that surplus production by choice may not be significantly high for the average Icelandic dairy farm. However, as shown in Table 1, there is significant variation across farms and over time. For the $83.4 \%$ of farms that exceeded their quota in some year, the average surplus production was $11.4 \%$ of the corresponding quota size during 1998-2006.

The translog production function for milk was specified with six inputs and a trend variable. The inputs are concentrates, capital, veterinary services, land, number of cows, and labor. Concentrates, capital, and veterinary services are measured in monetary units that are deflated to 1998 prices using the consumer price index for agricultural products. Land is measured in hectares, and the number of cows is measured in cow-years, which is a weighted aggregate of the number of cows on a farm. The number of days in a year a cow has been active in milk production, or days in milk, is used for weighting. Labor use is measured as labor months per year. The descriptive statistics of these inputs are provided in Table 1.

The use of all inputs except for labor has increased over time. The largest increase is in capital and concentrates, which have increased by $15.6 \%$ and $6.5 \%$ per year, respectively. The number of cows increased by $1.7 \%$, and quota size increased by $5.6 \%$ per year. These changes in input use are indicative of the significant structural adjustment that has occurred in the Icelandic dairy sector since 1992. 


\section{Results}

All the variables were normalized through a division by their respective geometric means before estimation. The normalization allows the interpretation of firstorder parameters as output elasticities at the geometric mean. The model is initially estimated by assuming an inefficiency term that is distributed as a truncated normal variable. However, the estimated value of the truncation point (i.e., $\mu$ ) was not significantly different from zero at any conventional level of significance. Therefore, the model is reestimated under the assumption of a half-normally distributed technical inefficiency term. The resulting parameter estimates are provided in Table 2. All output elasticities are positive and significantly different from zero at the $5 \%$ level of significance. This result implies that the estimated production frontier is monotonic with respect to inputs at the geometric mean. However, monotonicity at the geometric mean does not guarantee that the output elasticities are positive at every data point. As shown by Berndt and Christensen (1973), the translog functional form does not satisfy monotonicity and curvature properties globally, nor can it be constrained to do so without losing its second-order flexibility (Sauer, Frohberg, and Hockman, 2006). Accordingly, for all data points where monotonicity is violated, the output elasticities are replaced with zeros prior to the construction of the aggregation weights. ${ }^{6}$

The parameter of the trend variable is positive and significantly different from zero at the $1 \%$ level. This result implies that there has been technical progress on Icelandic dairy farms. This outcome is expected because milk yield per cow increased by 32\% between 1990 and 2007 (The Farmers Association of Iceland, 2009). Several changes in the Icelandic dairy sector can explain this increase (see Atsbeha, Kristofersson, and Rickertsen, 2012).

The average technical efficiency score for Icelandic dairy farms is $85.3 \%$. This score suggests that the average farm can reduce its inputs by $14.7 \%$ to produce its output. ${ }^{7}$ Furthermore, the decay parameter for technical inefficiency is negative, which suggests that technical efficiency declined during the study period. Atsbeha, Kristofersson, and Rickertsen (2012) also found the same result for Icelandic dairy farms, and they provided some explanations for the decline relating to the managerial challenges of transition to large-scale production and the learning curve that is associated with the optimal employment of new

6 For the estimation sample, the percentage of the negative output elasticities range between $0.4 \%$ for concentrates and $27.3 \%$ for veterinary services.

7 If there is information about farm and farmer characteristics, as well as other efficiency-determining factors such as access to infrastructure, credit, extension services, and so forth, it is possible to generate useful recommendations on the actual mechanisms required to reduce input use. In particular, a second equation can be estimated simultaneously with the production function regressing technical efficiency scores on efficiency-determining factors. More details about this approach can be seen in Wang and Schmidt (2002). 
Table 2. Parameters of the Milk Production Function in Iceland, 1998-2006

\begin{tabular}{|c|c|c|c|c|c|c|c|c|}
\hline Variables & $\begin{array}{l}\text { First } \\
\text { Order }\end{array}$ & Concentrates & Capital & $\begin{array}{l}\text { Veterinary } \\
\text { Services }\end{array}$ & Land & $\begin{array}{l}\text { Number } \\
\text { of Cows }\end{array}$ & Labor & Trend \\
\hline Constant & $\begin{array}{l}0.164^{* * * *} \\
(0.000)\end{array}$ & & & & & & & \\
\hline Concentrates & $\begin{array}{l}0.234^{* * *} \\
(0.000)\end{array}$ & $\begin{array}{l}0.087^{* * * *} \\
(0.000)\end{array}$ & & & & & & \\
\hline Capital & $\begin{array}{l}0.074^{* * * *} \\
(0.000)\end{array}$ & $\begin{array}{c}-0.069^{* * *} \\
(0.001)\end{array}$ & $\begin{array}{c}0.097 \\
(0.208)\end{array}$ & & & & & \\
\hline Veterinary services & $\begin{array}{l}0.023^{* * * *} \\
(0.000)\end{array}$ & $\begin{array}{c}0.027^{*} \\
(0.012)\end{array}$ & $\begin{array}{l}0.004^{* *} \\
(0.019)\end{array}$ & $\begin{array}{c}0.003 \\
(0.204)\end{array}$ & & & & \\
\hline Land & $\begin{array}{c}0.075^{* *} \\
(0.044)\end{array}$ & $\begin{array}{r}-0.087 \\
(0.170)\end{array}$ & $\begin{array}{c}0.022 \\
(0.851)\end{array}$ & $\begin{array}{r}-0.079 \\
(0.820)\end{array}$ & $\begin{array}{r}-0.006 \\
(0.140)\end{array}$ & & & \\
\hline Number of cows & $\begin{array}{l}0.558^{* * *} \\
(0.000)\end{array}$ & $\begin{array}{c}-0.135^{* *} \\
(0.026)\end{array}$ & $\begin{array}{r}-0.049 \\
(0.591)\end{array}$ & $\begin{array}{l}0.022^{* * *} \\
(0.005)\end{array}$ & $\begin{array}{c}0.069 \\
(0.941)\end{array}$ & $\begin{array}{c}0.333 \\
(0.758)\end{array}$ & & \\
\hline Labor & $\begin{array}{l}0.103^{* * *} \\
(0.000)\end{array}$ & $\begin{array}{l}0.005^{* * *} \\
(0.002)\end{array}$ & $\begin{array}{r}-0.041 \\
(0.354)\end{array}$ & $\begin{array}{c}0.026 \\
(0.525)\end{array}$ & $\begin{array}{c}0.032 \\
(0.328)\end{array}$ & $\begin{array}{c}-0.133^{* * *} \\
(0.000)\end{array}$ & $\begin{array}{c}0.109^{*} \\
(0.064)\end{array}$ & \\
\hline Trend & $\begin{array}{l}0.025^{\text {**** }} \\
(0.000)\end{array}$ & $\begin{array}{c}0.007 \\
(0.887)\end{array}$ & $\begin{array}{r}-0.010 \\
(0.356)\end{array}$ & $\begin{array}{r}-0.006 \\
(0.353)\end{array}$ & $\begin{array}{r}-0.003 \\
(0.549)\end{array}$ & $\begin{array}{c}0.021^{*} \\
(0.085)\end{array}$ & $\begin{array}{c}0.008 \\
(0.175)\end{array}$ & $\begin{array}{r}-0.009 \\
(0.426)\end{array}$ \\
\hline $\begin{array}{l}\sigma_{\varepsilon}^{2} \\
\psi^{\mathrm{b}}\end{array}$ & $\begin{array}{l}0.067 \\
0.791\end{array}$ & \multicolumn{4}{|c|}{$\begin{array}{l}\text { Average technical efficiency score } \\
\qquad \eta=-0.038(0.013)\end{array}$} & $85.4 \%$ & & \\
\hline
\end{tabular}

a Notes: Asterisks $\left({ }^{* * *},{ }^{* *}\right.$, and $\left.{ }^{*}\right)$ indicate significance at the $1 \%, 5 \%$, and $10 \%$ levels, respectively. $P$ values in parentheses.

${ }^{\mathrm{b}} \psi=\frac{\sigma_{u}^{2}}{\sigma_{v}^{2}+\sigma_{u}^{2}}$. 
Table 3. Overproduction Probabilities and Relative Marginal Importance of Price Changes in the Quota Milk Market of Iceland, 1998-2006

\begin{tabular}{|c|c|c|c|c|c|c|c|}
\hline \multirow[b]{3}{*}{ Year } & \multicolumn{5}{|c|}{ Aggregate Input Approach } & \multirow{2}{*}{\multicolumn{2}{|c|}{$\begin{array}{l}\text { Single Input } \\
\text { Approach }\end{array}$}} \\
\hline & & \multicolumn{3}{|c|}{ Overproduction By } & \multirow[b]{2}{*}{$\Theta_{q}$} & & \\
\hline & $\Phi$ & $1 \%-3 \%$ & $3 \%-7 \%$ & $>7 \%$ & & $\Phi$ & $\Theta_{q}$ \\
\hline 1998 & 0.650 & 0.084 & 0.174 & 0.338 & 0.259 & 0.803 & 0.167 \\
\hline 1999 & 0.686 & 0.123 & 0.171 & 0.366 & 0.240 & 0.822 & 0.149 \\
\hline 2000 & 0.654 & 0.146 & 0.205 & 0.224 & 0.265 & 0.787 & 0.182 \\
\hline 2001 & 0.649 & 0.123 & 0.202 & 0.271 & 0.279 & 0.790 & 0.181 \\
\hline 2002 & 0.691 & 0.105 & 0.234 & 0.368 & 0.248 & 0.830 & 0.144 \\
\hline 2003 & 0.671 & 0.113 & 0.251 & 0.270 & 0.271 & 0.826 & 0.149 \\
\hline 2004 & 0.645 & 0.102 & 0.200 & 0.349 & 0.247 & 0.861 & 0.118 \\
\hline 2005 & 0.613 & 0.064 & 0.137 & 0.174 & 0.276 & 0.772 & 0.201 \\
\hline 2006 & 0.616 & 0.085 & 0.138 & 0.247 & 0.275 & 0.792 & 0.181 \\
\hline Mean & 0.650 & 0.104 & 0.187 & 0.287 & 0.262 & 0.809 & 0.164 \\
\hline
\end{tabular}

technologies. Also see Alvarez and Arias (2003) for a similar finding about the link between managerial ability and size efficiency.

Next, an aggregate input is constructed based on farm- and time-specific weights, as in equation (4). The average aggregate input level is 481 units with a standard deviation of 222.4. The average yield per unit of the aggregate input is 386.3 liters with a standard deviation of 151.5. The average yield requirement per unit of aggregate input is 321.1 liters with a standard deviation of 130.1 liters. Concerning the yield per cow data, the average number of cows is 31.8 with a standard deviation of 12.6. The average yield per cow is 5,328 liters with a standard deviation of 1,073.2 liters. The average yield requirement per cow is 4,455.6 liters with a standard deviation of 1,162.1 liters. These figures imply a coefficient of variation of $39.2 \%$ and $20.1 \%$ for the yield data that are computed per aggregate input and per cow, respectively. The moderate variation in yield per cow is as expected, given that Icelandic dairy production is largely based on the Icelandic dairy cattle, a breed with relatively smaller population and hence limited genetic diversity with respect to milk yield. In contrast, a larger variation is observed in the yield per aggregate input, which implies that most of the variation in milk production arises from differences in the application of other inputs than cows and management practices.

To estimate the yield density functions, the SuppDists package (Wheeler, 2009) written for $\mathrm{R}$ is used. For both yield data sets, the Johnson $S_{U}$ is selected as the best-fit functional form. The parameters of the empirical yield density functions are $\gamma=-0.88, \delta=1.47, \xi=212.64$, and $\lambda=137.9$ for the yield per aggregate input data and $\gamma=-0.04, \delta=1.27, \xi=4619.12$, and $\lambda=735.57$ for the yield per cow data. Computed from these empirical yield density functions, Table 3 shows the probabilities that planned production each year may exceed the quota 
and the relative marginal importance of a price change in the quota milk market each year. As computed from the yield per aggregate input density function, the probability that the average Icelandic dairy farm will overproduce its quota is 0.65 . This figure has shown a downward trend especially in the second half of the study period, with a peak at 0.69 in 2002 and its lowest point of 0.61 in 2005. Furthermore, the likelihood that overproduction is a mere consequence of an optimization error is low. This can be seen from the probabilities of overproducing the quota by different percentages. As shown in Table 3, the likelihood of overproducing the quota by $1 \%$ to $3 \%$ is consistently lower in all years than overproducing the quota by $3 \%$ or more.

Next, the relative marginal importance of price changes in the quota milk market is computed as shown in equation (2a). The results that are reported in Table 3 show that the relative marginal importance of a price change in the quota milk market to milk supply response is 0.26 on average. This result implies that the supply response to a price change in the quota milk market is on average less than one-third of the response to an equivalent and simultaneous price change in both markets. Alternatively, a price change in the surplus milk market is approximately three times more effective in motivating milk supply response by Icelandic dairy farms than an equivalent price change in the quota milk market. As noted by a referee, the expected nature of yield shocks (i.e., whether shocks are presumed systemic or idiosyncratic) may be important for the strength of supply responses in the surplus milk market. For example, when yield shocks are presumed to be idiosyncratic, the expected consequent effect on total supply could be small. This effect, in turn, lowers expectations concerning prices in the surplus milk market and dampens the supply response to price changes in the surplus milk market. The reverse is true when yield shocks are expected to be systemic because of the significant negative effects of systemic yield shocks on total milk supply.

Finally, the previous computations were made based on the empirical yield density function that is estimated from the yield per cow data. As shown in Table 3, the average probability that an Icelandic dairy farm will exceed its quota is 0.81 . As a result, the computed relative marginal importance of price changes in the quota milk market is lower by approximately 10 percentage points than the comparable estimate reported previously. The difference in these estimates is also tested for statistical significance using Wilcoxon's signed-rank test for paired data. The null hypothesis for the test is that the median of the difference between the estimates from the two approaches is zero. For the overproduction probabilities $(\Phi)$, the test statistic is $z=-14.97(p>|z|=0.0001)$, and for the relative marginal supply response measures $\left(\Theta_{q}\right)$, the test statistic is $z=10.72$ $(p>|z|=0.0001)$. In both cases, the difference in results between the two approaches is statistically significant at the $1 \%$ level.

As expected, these results show that the use of a single input to obtain yield data in a multiple input setting risks the possibility of inflated overproduction 
probabilities and therefore downplays the relative marginal importance of price changes in the quota output market. This result is likely the consequence of a yield density function estimated from yield data that portray a single input as more productive than farmers believe. In this case, the observed input choices by farmers will suggest the overapplication of the input and, therefore, lead to higher likelihoods of excess production.

\section{Conclusions}

Under marketing quota programs, dairy farms may plan to overproduce their quota if yield is uncertain. Such tendencies of excess production in quotaregulated systems because of yield uncertainty are usually explored for crop production. However, marketing quotas are also pervasive in the dairy sectors of the developed world. Furthermore, although to a lesser extent, livestock production is also subjected to yield uncertainty that arises from weatherrelated risks in feed production, diseases, death of animals, and reproductive performance. In addition, when quota programs are enforced through two-tier price systems, the relative importance of prices in the quota and surplus output markets as supply management tools is not obvious beforehand.

In this article, the likelihoods of excess production and the relative importance of price changes in a two-market setup were investigated for Icelandic dairy farms. Because of the country's geographic location, agriculture in Iceland takes place under difficult agroecological conditions that complicate husbandry practices and tend to exacerbate yield uncertainty. The effects of yield uncertainty and the relative importance of prices in a two-market setup were studied using a method proposed by Borges and Thurman (1994). This method selects a single input and assumes the yield density is unaffected by the application of other inputs. Given the multiple input nature of agriculture and the implications of the simplifying assumption on the likelihoods of overproduction, the method was modified to consider multiple inputs. The modification was implemented by aggregating the inputs based on weights obtained from a parametric production frontier.

The results showed that the average probability of planned production exceeding quota was 0.65 , which indicates that the average Icelandic dairy farm is likely to choose input levels planning to overproduce its quota. The likelihood of optimization error as the reason for overproduction was also low. An implication of these observations was that farmers attach more importance to the risk of quota shortfalls than to the risk of potentially low prices in the surplus milk market. This behavior was as expected given that surplus milk prices are increasingly becoming closely comparable with prices in the quota milk market. From a policy point of view, it is useful to note that the relative marginal importance of a price change in the surplus milk market was nearly three times as high as an equivalent price change in the quota milk market. 
The likelihood of overproduction was also computed with an approach that considers a single input only (i.e., cows) under the assumption that the yield per cow density function is unaffected by the application of other inputs. The results showed that the probability of exceeding the quota increases by approximately 16 percentage points, and the relative marginal importance of price changes in the quota milk market decreases by approximately 10 percentage points. These differences were also statistically significant at the $1 \%$ level of significance. A plausible explanation for the difference was that the yield data per single input portray the specific input as more productive than it is perceived to be by farmers. The observed levels of the input will then appear as an overapplication, which in turn leads to an exaggeration of overproduction probabilities.

\section{References}

Agnarsson, S. "A Tale of Two Quota Systems." Paper presented at the 11th Annual Conference of the International Society for New Institutional Economics (ISNIE), Reykjavik, Iceland, June 21-23, 2007.

Alston, J.M., and J.J. Quilkey. “Insurance Milk.” Australian Journal of Agricultural Economics 24,3(1980):283-90.

Alvarez, A., and C. Arias. "Diseconomies of Size with Fixed Managerial Ability." American Journal of Agricultural Economics 85,1(2003):134-42.

Atsbeha, D.M., D. Kristofersson, and K. Rickertsen. "Animal Breeding and Productivity Growth of Dairy Farms.” American Journal of Agricultural Economics 94,1(2012):9961012.

Babcock, B.A. “Acreage Decisions under Marketing Quotas and Yield Uncertainty.” American Journal of Agricultural Economics 72,4(1990):958-65.

Babcock, B.A., and D.A. Hennessy. "Input Demand under Yield and Revenue Insurance." American Journal of Agricultural Economics 78,2(1996):416-27.

Battese, G.E., and T.J. Coelli. "Frontier Production Functions, Technical Efficiency and Panel Data: With Application to Paddy Farmers in India.” Journal of Productivity Analysis 3,1-2(1992):153-69.

Berndt, E.R., and L.R. Christensen. "The Translog Function and the Substitution of Equipment, Structures, and Labor in U. S. Manufacturing 1929-68." Journal of Econometrics 1,1(1973):81-113.

Bjarnadottir, E., and D.M. Kristofersson. “The Cost of the Icelandic Transferable Dairy Quota System.” Icelandic Agricultural Sciences 21(2008):29-37.

Borges, R.B., and W.N. Thurman. "Marketing Quotas and Random Yields: Marginal Effects of Infra-Marginal Subsidies on Peanut Supply." American Journal of Agricultural Economics 76, (1994):809-17.

Christensen, L.R., D.W. Jorgenson, and L.J. Lau. "Transcendental Logarithmic Production Frontiers." Review of Economics and Statistics 55,1(1973):28-45.

The Farmers Association of Iceland. Icelandic Agricultural Statistics 2009. Reykjavik, Iceland: The Farmers Association of Iceland, 2009. Internet site: http://bondi.lbhi.is/lisalib/ getfile. aspx? itemid $=2211$ (Accessed November 3, 2016).

Fraser, R.W. "A Note: A Clarification of the Role of Yield Uncertainty in Influencing OverQuota Production.” Australian Journal of Agricultural Economics 39,2(1995):165-69. 
Goodwin, B.K., and A.P. Ker. "Modeling Price and Yield Risk.” A Comprehensive Assessment of the Role of Risk in U.S. Agriculture. R.E. Just and R.D. Pope, eds. Boston, MA: Kluwer Academic, 2002, pp. 289-323.

Hill, I.D., R. Hill, and R.L. Holder. "Fitting Johnson Curves by Moments." Applied Statistics 25,2(1976):180-89.

Jóhannesson, T. Agriculture in Iceland: Conditions and Characteristics. Hvanneyri, Borgarnes: Agricultural University of Iceland, 2010. Internet site: http://www.lbhi.is/ sites/default/files/gogn/vidhengi/thjonusta/utgefid_efni/RitLbhi/Rit_31_ICELANDIC_ AGRICULTURE.pdf (Accessed November 3, 2016).

Johnson, N.L. "Systems of Frequency Curves Generated by Methods of Translation." Biometrika 36, 1-2(1949):149-76.

Johnson, N.L., S. Kotz, and N. Balakrishnan. Continuous Univariate Distributions. Vol. 1. 2nd ed. New York: John Wiley and Sons, 1994.

Ker, A.P., and K. Coble. "Modeling Conditional Yield Densities." American Journal of Agricultural Economics 85,2(2003):291-304.

Ker, A.P., and B.K. Goodwin. "Nonparametric Estimation of Crop Insurance Rates Revisited." American Journal of Agricultural Economics 82,2(2000):463-78.

Kim, H.Y. "The Translog Production Function and Variable Returns to Scale." Review of Economics and Statistics 74,3(1992):546-52.

Nelson, C.H., and P.V. Preckel. "The Conditional Beta Distribution as a Stochastic Production Function.” American Journal of Agricultural Economics 71,2(1989):370-78.

Organization for Economic Cooperation and Development (OECD). Agricultural Policies in OECD Countries: Monitoring and Evaluation. Paris: OECD, 2007.

Ramirez, O.A., T.U. McDonald, and C.E. Carpio. "A Flexible Parametric Family for the Modeling and Simulation of Yield Distributions." Journal of Agricultural and Applied Economics 42,2(2010):303-19.

Sauer, J., K. Frohberg, and H. Hockman. "Stochastic Efficiency Measurement: The Curse of Theoretical Consistency." Journal of Applied Economics 9,1(2006):139-65.

Slifker, J.F., and S.S. Shapiro. "The Johnson System: Selection and Parameter Estimation." Technometrics 22,2(1980):239-46.

Wang, H.-J., and P. Schmidt. "One-Step and Two-Step Estimation of the Effects of Exogenous Variables on Technical Efficiency Levels." Journal of Productivity Analysis 18,2(2002) 129-44.

Wheeler, B. "SuppDists: Supplementary Distributions.” R Package Version 1.1-8, 2009. Internet Site: http://CRAN.R-project.org/package=SuppDists (Accessed November 3, 2016).

Wheeler, R.E. "Quantile Estimators of Johnson Curve Parameters. Biometrika 67,3(1980):725-28.

\section{Appendix A}

This appendix shows the implication of using a single input to compute yield in a multiple input setting on the estimation of overproduction probabilities. Assume a multiple input production and let $y^{b}$ be the yield of an input $x_{1}$ computed without taking the contribution of all other inputs to total output into account, and let $y^{a}$ be the yield of $x_{1}$ computed after taking the contribution of all other inputs to total output into account. Then, to the extent the marginal product of all other inputs is 


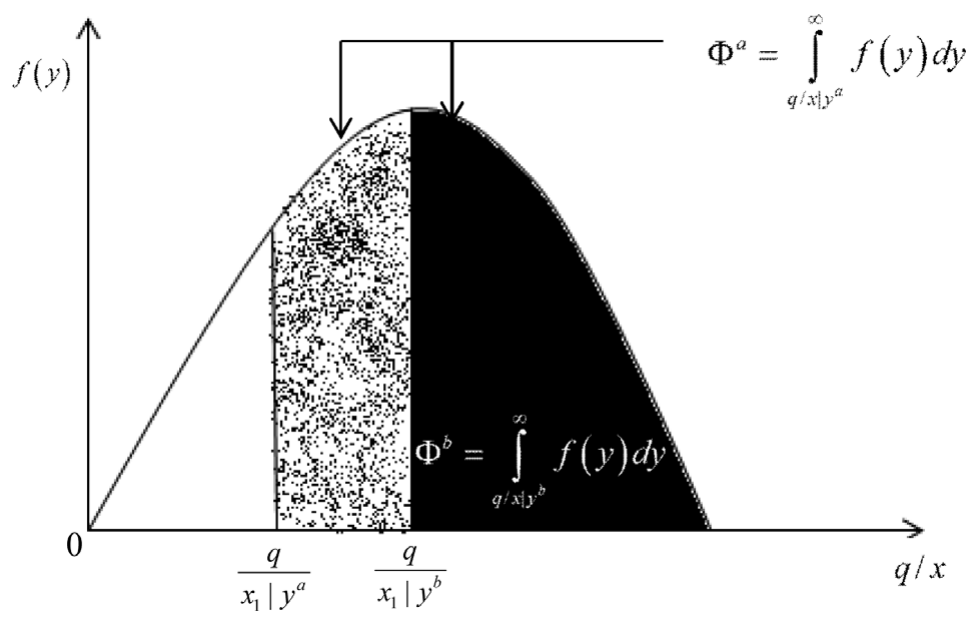

Figure A1. Probabilities of Excess Production under Two Ways of Computing Yield

positive, $y^{b}>y^{a}$; that is, any single input used to compute yield is going to appear more productive than it actually is when multiple inputs are involved to generate total output. Note, however, that farmers are likely to acknowledge the contribution of all inputs as they make their input choices, and the observed quantities of input $x_{1}$ are more likely to be made expecting $y^{a}$ per unit of $x_{1}$ rather than $y^{b}$. Therefore, at any planned level of output and keeping all other input choices constant, $x_{1}\left|y^{b}<x_{1}\right| y^{a}$. If this is the case, then the yield requirement to meet the quota exactly is bigger when farmers expect $y^{b}$ than $y^{a}$ or $\frac{q}{x_{1} \mid y^{b}}>\frac{q}{x_{1} \mid y^{a}}$. Then, for any given yield distribution, $\Phi^{a}=$ $\int_{q / x \mid y^{a}}^{\infty} f(y) d y>\Phi^{b}=\int_{q / x \mid y^{b}}^{\infty} f(y) d y$; that is, the overproduction probability is larger when the yield density is evaluated under input choice made by farmers expecting $y^{a}$ (as in Borges and Thurman [1994] because they used observed acreage data to evaluate the empirical yield density) than farmers expecting $y^{b}$. An implication is that the relative importance of price changes in the quota market for supply response will decline because $\lim _{q / x \rightarrow 0} \Theta_{q}=0$. This effect is shown graphically in Figure A1. 